\title{
Concussion among Swedish elite ice hockey players
}

\author{
Yelverton Tegner, Ronny Lorentzon
}

\begin{abstract}
Objective-To evaluate the frequency of concussion in Swedish ice hockey and to establish a uniform grading and treatment model for concussions of different severity.

Methods-Frequency of concussion was investigated in two studies, one retrospective and one prospective. In the retrospective study, all Swedish elite ice hockey players $(n=265)$ were asked to answer a questionnaire on the number and treatment of previous concussions. Only concussions diagnosed by a doctor were recorded. The questionnaire was completed by 227 players $(86 \%)$. In the prospective study, all injuries including concussions occurring during game and practice in the Swedish Elite League $(n=12$ teams) were recorded during four years. The causes of injury, referees judgements, diagnosis, treatment, and time absent from ice hockey were registered on special cards.
\end{abstract}

Results-In the retrospective study, 51 out of 227 players (22\%) in the Swedish Elite League reported at least one concussion. In the prospective study, 52 concussions were reported. The incidence of a concussion is at least one concussion every year/team or a yearly risk of about $5 \%$ for a player to sustain a concussion. Most concussions occurred during league play $(81 \%)$. Body contact (checking or boarding) was the most common cause of concussions. The players were absent from full training and play on a mean of $6 \mathrm{~d}$.

Conclusions-As this injury is potentially dangerous it must be treated seriously according to a simple treatment model presented. In cases of repeated concussions during the same season, a longer period of time away from play is suggested. In players who have sustained several concussions over the years a thorough medical examination including EEG, CT/ MRI, and neuropsychological tests should be performed. If any of these is pathological the player should be advised to give up ice hockey.

(Br F Sports Med 1996;30:251-255)

Key terms: ice hockey; concussion; management; incidence

In ice hockey there are many potential dangers because of frequent and often forceful player contacts and contacts with boards or goal posts. The injury incidence is high, but most injuries are not serious, that is, the majority of players can return to game and practice within a week. ${ }^{1-3}$

In Swedish ice hockey, it has been compulsory to wear a helmet since 1963. Before that, 16 deaths due to head injuries had been reported over a 10 year period. Since the legislation no deaths from head injury have occurred in Swedish ice hockey. ${ }^{4}$

Concussion still occurs among ice hockey players and constitutes between $2 \%$ and $14 \%$ of all ice hockey injuries. ${ }^{1-7}$ Differences in reported incidences can mainly be explained by variations in study design and in discrepancies in the definition of an injury. As far as we know there is no consensus of the definition of the milder forms of concussion. ${ }^{8}$

Concussions are potentially dangerous. In most instances, the injury will resolve without any residual symptoms. Concussion has often been regarded as a minor injury. However, several years ago it was shown that there are widespread microscopic changes within the brain after head trauma. ${ }^{9}$ Several reports of lesions detected by magnetic resonance imaging (MRI) have been published, indicating the severity of these injuries. ${ }^{10-12}$ Reports concerning the catastrophic outcome after a second injury have been reported. ${ }^{13-15}$ The cumulative effect of concussions has long been recognized. ${ }^{16-18}$ Several investigators have pointed out that treatment for concussion should aim at reducing the risk of a second injury, and they have also created recommendations of how to reduce this risk. ${ }^{819-27}$

In this investigation we aimed to study the risk of sustaining a concussion during Swedish elite ice hockey, to evaluate the present treatment model for concussions and, if found necessary, to create new recommendations for treatment of these injuries among ice hockey players. The main part of this investigation is prospective and covers injuries in the whole Swedish elite league during four seasons.

\section{Methods}

This study consists of two parts - one retrospective questionnaire study concerning previous concussions, and one prospective investigation covering four ice hockey seasons $(1988 / 89$ - 1991/92) in the Swedish elite ice hockey league. The players in the Swedish elite ice hockey league are semiprofessional and play 40-55 league games per year.

Before the start of the ice hockey season of 1988-1989, the team physicians of all teams in 
the Swedish highest ice hockey division (elite league) attended an information meeting concerning the background and purpose of the investigation. The physicians were thoroughly instructed in how to fill in the protocols for the studies and were informed about injury definitions.

\section{RETROSPECTIVE STUDY}

The questionnaire was to be completed by the players together with the team physicians. It included the following questions: Have you had any concussions? If so, how many? When did they happen? Were you away from play/training because of the concussion? If so, for how many days?

In this part of the study there was no uniform definition of concussion and therefore only concussion diagnosed by a doctor was to be recorded: this required the player to have been unconscious; minor concussion, without loss of consciousness, was not recorded.

\section{PROSPECTIVE STUDY}

The prospective study included registration of concussions, and also of all injuries that occurred during game or practice and forced the player to stop playing or to miss the next practice session(s) or game(s). All these injuries were recorded on a special card. On this card the causes of injury, referees judgements, diagnosis, treatment, and time absent from ice hockey were recorded and these cards were then sent to one of the authors (YT), who computerised all the data. Thus clinical examinations and registrations were always performed by the team physicians.

In order to have a more uniform definition and treatment of concussions, the team physicians agreed to the following procedure: (1) grade 1 concussion was defined as dizziness ("bell ringer") after a head trauma. No amnesia or unconsciousness should be present. Players in this group should stop playing and if symptom-free they were allowed to return to play the day after injury; (2) grade 2 concussion existed if the player had been unconscious for less than 30 seconds, or if he had amnesia. The players had to "rest" (see below), but could start full game playing one week after the first symptom-free day. (3) grade 3 concussion existed if the player had been unconscious for more than 30 seconds. This group of players was allowed to participate in full game and practice activities three weeks after the first symptom-free day. During the time absent from games, the players with grade 2 or 3 concussions were allowed to perform alternative training-that is, training without risk of sustaining a new trauma to the head. This meant that the players could participate in all ice training that did not involve training in game-like situations.

During the study period the teams in the elite ice hockey league played a total of 888 league games. For purposes of calculating the incidence of injury during games, 12 players were assumed to be on the ice at any one time, making a total of 8736 player-game-hours. During the study period some team physicians
Table 1 Distribution of concussions relative to the cause.

\begin{tabular}{lll}
\hline Cause & No & $\%$ \\
\hline Body checking & 27 & 56 \\
Boarding & 13 & 26 \\
Hit by stick & 3 & 6 \\
Hit by puck & 2 & 4 \\
Miscellaneous & 4 & 8 \\
Unknown & 3 & Not included \\
Totals & 52 & 100 \\
\hline
\end{tabular}

did not cooperate to a full extent and reported very few injuries for a certain year. Therefore teams that reported a total of less than 10 injuries of all kinds per year were excluded (regardless whether these excluded injuries were concussions or not). In this way, we excluded a total of 10 teams yearly reports during the four year study period. After exclusion of these teams the total number of games played was 628 and a total of 7536 playergame-hours. Since there were 8736 playergame-hours for all teams, our study covers 86.2 per cent of all player-game-hours in the Swedish elite league during four seasons.

\section{Results}

RETROSPECTIVE STUDY

Eleven of the 12 teams participated in this part of the study. In these teams, there was a total of 265 players and $227(86 \%)$ of them answered the questionnaire. Fifty one (22\%) had had a total of 87 concussions during their whole ice hockey career; 38 players reported one concussion, 11 reported two to five concussions, and two reported more than five concussions (six and nine, respectively).

\section{PROSPECTIVE STUDY}

During the four seasons a total of 805 injuries was reported. Fifty two $(6 \%)$ of these injuries were concussions. A total of 480 different players in 14 different teams played in the highest league during these four years, and 43 players (9\%) sustained at least one concussion; three players had three concussions, and three players had two concussions, making a total of 52 concussions.

Most concussions ( $n=42)$ appeared during league games and the rest in practice games $(n=7)$ or during practice $(n=3)$.

The risk of sustaining a concussion during league play could be calculated to $6.5 / 1000$ player-game-hours or approximately one concussion per team each season.

Body contact, either body checking or boarding was the most common reason for a concussion (table 1). Concussions due to the stick and the puck accounted for only $10 \%$.

In 45 cases the injury was considered accidental by the referee as it did not result in a penalty for the opponent. In six cases a two minute penalty was called and in one case a five minute penalty.

Fifty four per cent of the concussions occurred in the second period, $30 \%$ in the first, and $16 \%$ in the third period. The differences were significant only between the second and third period $\left(\chi^{2}=9.71 ; P<0.01\right)$. 
Table 2 Absence from full participation in training and games.

\begin{tabular}{ll}
\hline Days of absence & Number of players \\
\hline Stopped game & 9 \\
$1-3 \mathrm{~d}$ & 17 \\
$4-6 \mathrm{~d}$ & 4 \\
$7-13 \mathrm{~d}$ & 14 \\
3 weeks & 3 \\
> 3 weeks & 3 \\
Stopped ice hockey playing & 2 \\
Total & 52 \\
\hline
\end{tabular}

The players were absent from full training and game play on a mean of 6 days. The distribution of days away from ice hockey is listed in table 2 .

Two players stopped playing ice hockey because of repeated concussions. One goal keeper had had 12 concussions during his career (1982-1990) and stopped playing as he developed signs of permanent brain injury. $\mathrm{He}$ had concentration problems, irritability, and impaired memory. Electroencephalogram (EEG) and computerised tomography (CT) were normal but a neuropsychological test showed clear evidence of brain damage. Three years after he stopped playing he still has residual symptoms, and a new neuropsychological test showed that there was persisting impairment of brain function. The other player was a young defenceman, who in a short time (two seasons) had had four concussions. Two of these occurred during junior ice hockey play. After his last concussion, he was advised to stop playing in order to avoid permanent brain damage. Three years after his last concussion, CT and EEG were normal and he had no symptoms of brain damage so he started to play again at a lower level.

During these four years, 35 of the 480 players sustained their first concussion.

When evaluating the both the studies-the retrospective and the prospective-94 (20\%) of all players had had at least one concussion. The number of concussions for all players is listed in table 3.

When analysing the effect of different player position on the incidence of concussions, we used data from both the retrospective and the prospective study. Seven players were goalkeepers, 24 defencemen, and 63 forwards. When we estimated that two goalkeepers, four defencemen, and six forwards were on the ice at any one time, we were unable to find any significant differences between the three groups.

\section{Discussion}

In the retrospective study our definition of concussion was that it should have been diagnosed by a physician. This means that minor concussions without unconsciousness ("bell ringers") were most probably not reported, as most physicians at this time were not aware of our extended definition of concussion.

It seems as if at least $20 \%$ of elite ice hockey players will sustain a concussion during their ice hockey career. This is a high figure, though
Table 3 Distribution of the number of concussions in 94 ice hockey players (retrospective and prospective studies taken together).

\begin{tabular}{ll}
\hline Concussions & No of players \\
\hline 1 & 70 \\
2 & 12 \\
3 & 4 \\
4 & 3 \\
5 & 2 \\
6 & 1 \\
7 & 1 \\
12 & 1 \\
Total & 94
\end{tabular}

not as high as in American football, where Gerberich $e t a l^{8}$ reported a yearly incidence of at least $19 \%$. In other contact sports like soccer, incidences of between $4 \%$ and $22 \%$ have been reported. ${ }^{29}$

Our prospective study covered $86.2 \%$ of all player-game-hours during the four year study period for the Swedish elite league teams. The reported incidence (approximately one concussion/year/team) is well in line with data from Lorentzon et $a l^{2}{ }^{2}$ who followed one elite team closely and recorded every injury during three years, reporting a yearly incidence of 1.3 concussions.

The reasons why most injuries occurred in the second period are unknown. The number of penalties in each period has been analysed but we could not find anything suggesting that the play was more aggressive in the second period. The number of penalties was evenly distributed over the different periods.

This study showed that most injuries were "accidental", at least as judged by the referees. This probably means that the game in itself involves many situations that can cause concussion. Another explanation is that the referees missed a number of intentional checks and blows. It is our belief that if the rules were more strictly followed by the players, and if the officials enforced rules against dangerous checking, there would be a reduction of concussions.

In 1985 the Swedish Medical Association ${ }^{30}$ recommended that athletes who had had a concussion should avoid competition for one to three weeks. The treatment model that we used in this study tallied well with these recommendations, and on the whole the recommendations were well followed by the team physicians. However, many players still return to play earlier than recommended, that is, after compulsory absence from games for one or three weeks depending on the severity of the concussion. As the original treatment model did not take full account of the cumulative effect of concussions we have modified it (table 4). Cantu ${ }^{20-22}$ has pointed out the need to have strict therapeutic schedules in the treatment of concussion in athletes. Our treatment model is in good agreement with his recommendations. Other investigators ${ }^{8192325}$ have also published recommendations on the treatment of concussion in athletes. It is not possible to say which model is best until very long term follow up studies have been reported. 
Table 4 Recommended treatment model for concussions.

\begin{tabular}{|c|c|c|c|}
\hline Type & $1^{s t}$ Concussion & $2^{\text {nd }}$ Concussion & $3^{\text {rd }}$ Concussion \\
\hline $\begin{array}{l}\text { Grade 1: } \\
\text { "Bell ringer" } \\
\text { No amnesia } \\
\text { Conscious }\end{array}$ & $\begin{array}{l}\text { Stop playing } \\
\text { Return to } \\
\text { play next day } \\
\text { if symptom- } \\
\text { free }\end{array}$ & $\begin{array}{l}\text { Stop playing } \\
\text { No game for } \\
7 \text { d } \\
\text { Alternative } \\
\text { training }\end{array}$ & $\begin{array}{l}\text { Stop playing } \\
\text { No game for } \\
21 \mathrm{~d} \\
\text { Alternative } \\
\text { training }\end{array}$ \\
\hline $\begin{array}{l}\text { Grade 2: } \\
\text { Amnesia or } \\
\text { unconscious } \\
\text { for }<30 \mathrm{~s}\end{array}$ & $\begin{array}{l}\text { Stop playing } \\
\text { no game for } \\
7 \mathrm{~d} \\
\text { Alternative } \\
\text { training }\end{array}$ & $\begin{array}{l}\text { Stop playing } \\
\text { No game for } \\
21 \mathrm{~d} \\
\text { Alternative } \\
\text { training }\end{array}$ & $\begin{array}{l}\text { Stop playing } \\
\text { Player not } \\
\text { allowed to } \\
\text { return until } \\
\text { next season }\end{array}$ \\
\hline $\begin{array}{l}\text { Grade 3: } \\
\text { Unconscious } \\
\text { for }>30 \mathrm{~s}\end{array}$ & $\begin{array}{l}\text { Stop playing } \\
\text { No game for } \\
21 \mathrm{~d} \\
\text { Alternative } \\
\text { training }\end{array}$ & $\begin{array}{l}\text { Stop playing } \\
\text { Player not } \\
\text { allowed to } \\
\text { return until } \\
\text { next season }\end{array}$ & \\
\hline
\end{tabular}

Ingersoll ${ }^{31}$ emphasises the need to have a strict rehabilitation programme for head injured athletes, as he-has shown that there are somatosensory deficits after a closed head injury.

In our treatment model we consider a bell ringer as a potentially serious injury and that the injured player should stop playing. As long ago as 1975 , Reilly et $a^{\beta 2}$ described the "talk and die syndrome", where apparently conscious patients suddenly deteriorate and die. This syndrome can occur after a simple bell ringer. It is also known that amnesia following a minor head injury can take several minutes to appear $^{33}$ and this underlines the necessity of regarding a minor bell ringer as potentially dangerous.

One practical problem of our therapeutic model is that in most instances the concussed ice hockey player is free of symptoms within a few days after the injury and wants to return to playing. Coaches also want the player back as soon as the symptoms have resolved. The players are allowed to perform alternative training-without body contact-during the time away from ice hockey, but this alternative training should not start until the player is free of symptoms.

Most players in these studies sustained only one concussion and in most instances it was minor, but many players sustained several concussions. As early as 1952 , Thorndike ${ }^{34}$ concluded that three concussions should preclude further participation in contact sports. This may be true, but the reparative processes in multiple concussions are not yet fully understood. If an ice hockey player has sustained several concussions of more than grade 1 severity, we definitely consider that he should undergo a thorough medical examination, including EEG, CT/MRI, and neuropsychological tests, in order to rule out or confirm permanent brain damage. If any of these examinations shows sign of brain damage, the athlete should be advised to give up ice hockey.

The helmet in ice hockey is effective in reducing fatal injuries ${ }^{4}$ but no helmet can completely protect the brain from injury. It is effective in preventing injuries from puck and stick impact, ${ }^{35}$ but in cases with higher impact forces there will be relative movement of the brain and the skull in response to the impact (contre-coup). This may produce a brain injury that cannot be protected against with helmets of today s design.

\section{CONCLUSION}

Concussion is a potentially serious injury, and around $20 \%$ of all elite ice hockey players will sustain at least one concussion during their career. In order to reduce the number of these injuries the players should follow the rules and the referees should enforce the rules relating to dangerous checking. It is necessary for the treatment of this injury to be strictly standardised to avoid catastrophic outcome. The suggested treatment model is simple and practical and can be used in sports other than ice hockey.

1 Jörgensen U, Schmidt-Olsen S. The epidemiology of ice hockey injuries. Br $\mathcal{F}$ Sports Med 1986;20:7--9.

2 Lorentzon R, Wedrén $H$, Pietilä T. Incidence, nature, and causes of ice hockey injuries. A three-year prospective study of a Swedish elite ice hockey team. Am 7 Sports Med 1988 ; 16:392--6.

3 Tegner Y, Lorentzon R. Ice hockey injuries: incidence, nature and causes. Br f Sports Med 1991;25:87-9. 4Idrottsskador 1976-1983 (Sports injuries 1976-1983). Re4Idrottsskador 1976-1983 (Sports injuries 1976-1983). Report from Swedish Insura

5 Castaldi CR, Sparacio L, Wood AS, Bernard J. Injury rates in amateur, college and professional hockey. In: Castaldi CR, Hoerner EF, eds. Safety in ice hockey. (ASTM STP 1050.) Philadelphia: American Society for testing and materials, 1989:14-28.

6 Feriencik K. Trends in ice hockey injuries: 1965 to 1977. Physician Sportsmeci 1979;7:81-4.

7 Hastings DE, Cameron J, Parker SM, Evans J. A study of hockey injuries in Ontario. Ontario Med Rev 1974;Nov: 686-692, 698 .

8 Henderson JM, Browning DC. Head trauma in young athletes. Sports Med 1994;78:289-303.

9 Nevin NC. Neuropathological changes in the white matter following head injury. $\mathcal{f}$ Neuropathol Exp Neurol 1967;26: following

10 Gentry LR, Godersky JC, Thompson B, Dunn VD Prospective comparative study of intermediate-field MRI and CT in the evaluation of closed head trauma. Am $\mathcal{F}$ Radiol 1988;150:673-82.

11 Jenkins A, Teasdale G, Hadley MDM, Macpherson $P_{\text {, }}$ Rowan JO. Brain lesions detected by magnetic resonance imaging in mild and severe head injuries. Lancet 1986;ii: 445-6.

12 Levin HS, Amparo E, Eisenberg HM, Williams DH, High WH, McArdle CB, et al. Magnetic resonance imaging and computerized tomography in relation to the neurobehaviocomputerized tom grad and moderate head injuries $f$ Neurosurg 1987;66:706-13.

13 Kelly JP, Nichols JS, Filley CM, Lillehei KO, Rubenstein D, KleinsmidtDeMasters BK. Concussion in sports. GuideleinsmidtheMasters BK. Concussion in sports. Guide-
lines for the prevention of catastrophic outcome. $f A M A$ lines for the preve

14 McQuillen JB, McQuillen EN, Morrow P. Trauma, sport, and malignant cerebral edema. Am $\mathcal{F}$ Forensic Med Pathol 1988;9:12-15.

15 Saunders RL, Harbaugh RE. The second impact in catastrophic contact-sports head trauma. $¥ A M A 1984 ; 252$ 538--9.

16 Gronwall D, Wrightson P. Cumulative effect of concussion. Lancet 1975;ii:995-7.

17 Gronwall D, Wrightson P. Memory and information processing capacity after closed head injury. $\mathcal{f}$ Neurol Neurosurg Psychiatry 1981;44:889-95.

18 McSherry JA. Cognitive impairment after head trauma. $A m$ Fam Physician 1989;40:186-90.

19 Bruno LA, Gennarelli TA, Torg JS. Management guidelines for head injuries in athletics. Clin Sports Med 1987;6:17-29. Cantu RC. Guidelines for return to contact sports after a Cantu RC. Guidelines for return to contact sports after

cerebral concussion. Physician Sportsmed 1986;14:75-83.
Cantu RC. When to return to contact sports after a cerebral Cantu RC. When to return to contact sports

concussion. Sports Med Dig 1988;10:1-2. Cantu RC. Cerebral concussion in sport.

23 prevention. Sports Med 1992;14:64-74. Colorado Medical Society: Guidelines for the mans
of concussions in sports. Colo Med 1990;87:4-6.

24 Hugenholtz H, Richard MT. Return to athletic competition following concussion. 7 Can Med Assoc 1982;127:827-9.

25 McLatchie G, Jennet B. Head injury in sports. BMF 1994;308:1620-4.

26 Roberts WO. Who plays? Who sits? Physician Sports Med 1992;20:66-72.

27 Wilberger JE, Maroon TC. Head injuries in athletes. Clin Sports Med 1989;8:1-9. 
28 Gerberich SG, Priest JD, Boen JR, Straub CP, Maxwell RE. Concussion incidences and severity in secondary school varsity football players. Am $f$ Public Health 1983;73: 1370-5.

29 Tysvaer AT. Head and neck injuries in soccer. Impact of minor trauma. Sports Med 1992;14:200-13.

30 Swedish Medical Association. Treatment of concussion in sports. Stockholm: Rikstämmans publication, 1985.

31 Ingersoll CD. Long term effect of closed head injury in sports. Sports Med 1993;16:342-54.
32 Reilly PI, Adams JH, Graham DI, Jenett B. Patients with head injury who talk and die. Lancet 1975;ii:375-7.

33 Yarnell PR, Lynch S. Retrograde amnesia immediately after Yancussion. Lancet 1970;ii:863-4.

34 Thorndike A. Serious recurrent injuries of athletes. Contraindications for further competitive participation. $N$ Engl ₹ Med 1952;247:554-6.

35 Ryan AJ. Protecting the sportsman s brain (concussion in sports). Br $\mathcal{F}$ Sports Med 1991;25:81-6.

1996 BASM ANNUAL CONGRESS

Thursday 31 October Sunday 3 November

at

Newcastle, Co Down Northern Ireland

SPORTS MEDICINE INTO THE 21st CENTURY

Keynote speakers:

Prof Per Renström

Prof David Costill

Vermont, USA

Indiana, USA

Dr Willem van Mechelen Amsterdam, Holland

Topics will include:

- Physiological, psychological and pharmacological limits to performance in sport, physical activity and health - new challenges for the health carers.

- The ankle - a complete overview of acute, recurring and chronic injury and its rehabilitation.

- Advances in imaging.

- Pre-hospital care of the acutely injured sportsman.

Scientific papers and posters will be presented and displayed. We are now looking for abstracts.

For further information regarding the scientific programme, abstract submission or booking arrangements please contact:

\author{
Dr Robin Harland MB FRCFGP FISM \\ 6 Castlehill Road \\ BELFAST BT4 3GL \\ Northern Ireland
}

Telephone: 01232653682 Fax: 01232473540

E-Mail: R.Harland@QUB.AC.UK

The setting for the 1996 Conference is in an area of outstanding beauty with facilities for many sporting activities. This is a perfect opportunity to combine a Conference of high standard with a short break in a new setting and to experience our famous Irish hospitality.

Full PGEA approval sought. 